\title{
Effectiveness of Teaching as the Main Result of the High School Education under the Conditions of Changes and Transition to the Digital Economy
}

\author{
Anna Egorenko \\ Financial University under the Government of the Russian \\ Federation \\ Moscow, Russia \\ E-mail: annaegorenko@yandex.ru
}

\author{
Irina Sheveleva \\ Pantheon-Sorbonne University \\ Sorbonne, France \\ E-mail: irishev@mail.ru
}

\begin{abstract}
The article is devoted to the constantly increasing role of the system for assessing the results of teaching work and its influence on teachers' motivation, the possibility to draw teachers' attention to certain strategic tasks of the university, the possibility of taking into account different aspects of teachers' activity, with human resource and financial planning, as well as the creating conditions in order to ensure the competitiveness of a higher educational institution. The changes in the content of teaching work are directly related to the formation of new educational strategies and policies by universities.
\end{abstract}

Keywords-teaching staff; effectiveness of the education system; management of scientific and pedagogical potential quality

\section{INTRODUCTION}

The effectiveness of teaching work is assessed with the use of various methods for assessing performance, which are created primarily to solve the task of stimulating labor. On the one hand, such ways of stimulating teaching work are naturally based on program and other documents of the Ministry of Education and Science of the Russian Federation, on the strategic goals set by the Government of the Russian Federation, on the other hand, they are based on the results of research in the field of economics and university management. Fulfilling teaching load and other types of teaching activities is paid according to the Unified Tariff System (UTS). Further differentiation of teachers' labor remuneration is carried out on the basis of other work done by the teacher, such as accompanying the educational process, scientific, educational and other activities. To take into account the implementation of these teaching functions, universities develop internal documents on additional incentive payments that imply the introduction and use of a score-rating system for assessing the performance of the teaching staff for the academic year or other periods preceding the period of setting the allowance.

The issues of transformation of assessment and incentive systems for teachers of higher education institutions are currently being paid much attention to, in particular, among such Russian authors as Evramova E.M., Alaev M.V., Belov
V.G., Voynov I.S., Gibova I.M., Gunchenko M.V., Kislov A.G., Klyachko T.L., Kondrakov G.B., Kosinova E.P., Kochetkova N.N., Loginov D.M., Makarenkova T.I., Masych M.A., Panichkina M.V., Parfenov Y.A., Titovsky A.V., Skorokhodova Y.V., Shcherbina E.Y. and others.

\section{The Role OF TEACHING STAFF AT UNIVERSITIES IN ENSURING THE QUALITY OF EDUCATION}

Currently the term "quality of education" is understood as a degree or measure of meeting a certain set of characteristics of education (as a system, process, and result) and established, presumed or mandatory expectations (needs). From this perspective, the management of education quality influences the system, process or result with the purpose of transferring a certain set of characteristics from a known initial state to the required final state. Here it is necessary to study two aspects of quality in education. On the one hand, the competence of graduates of the university is characterized in accordance with the requests of customers and the requirements of state standards. On the other hand, systemic capabilities of graduates' qualification are revealed and it is implied that the quality of results is determined by the quality of the resources and processes of the institution. Moreover, if the former aspect used to prevail before, now the role of the second aspect is rapidly growing.

Being inertial and having delayed consequences from impacts, the system of education, which is implemented in each university, should strive to adequately forecast its development and prevent the emergence of processes that reduce the quality of its functioning. In the structure of the education system we can distinguish a triad: subject-toolobject. The subject is the heads of the educational institution as decision-makers, the tool is the teaching staff, the object is the students who are studying at the university. The main task of ensuring the quality of higher education is the compliance of the teaching staff of universities with the modern requirements for teaching [1]. Whatever reforms are carried out in the educational environment, they boil down to the teacher as a performer. The level of pedagogical staff potential identifies the quality of the university's activity, at 
the same time it is one of the main objects of management in the conditions of modernization of higher education.

According to the university structure established in Russia, teachers work at departments with their disciplines fixed, they also perform educational, scientific and organizational assignments according to their qualifications, and also have the opportunity to periodically improve their qualifications. When hiring new teachers, a higher educational institution can also guarantee the acquisition of a high level of professional knowledge and the necessary range of competencies. It goes without saying that most teachers already have comprehensive knowledge of the subject area, as well as the necessary skills and experience for effective transfer of knowledge to students in the educational process. [2] Nevertheless, the success of high professional activity of teachers in higher education is determined not only by subject knowledge, but also by the high level of general cultural competences, by the correlation of personality-psychological factors that act as separate elements of a unified system. A highly professional teacher is able not only to implement his or her pedagogical activity, but also to improve its foundations, methods and means. Professional self-realization of the teacher is connected with social life, which is largely determined by qualifications and experience. Among the reasons that affect the decline in the level of personal and professional development we can identify the following [3]:

- Lack of capacity for planning and self-organization;

- Low responsibility in self-development;

- Inability to make flexible and adequate decisions in accordance with the situation;

- Lack of interest in the results of teaching activity.

Dealing with these causes of crisis is within the abilities of a teacher, his or her value orientations, strong-willed qualities, adequate reactions to situations in pedagogical activity, the ability to make some changes in daily work and practice. The effectiveness of teaching activities also depends on the psychological characteristics of the teacher him/herself, his/her value priorities [4].

Higher education in Russia repeats the world trends of transition from the higher school of industrial design to the higher school of the postindustrial period, as evidenced by the trends that have developed over the past 15-20 years: education is becoming more massive, there is an increase in competition for limited resources between universities. The main directions of the development of the university autonomy are the search for new forms, the balance of powers and responsibility of the bodies of collegial management, the separation of academic and administrative management, the strengthening the role of expert structures in the management system of the university.

\section{EFFECTIVENESS OF MANAGING THE DEVELOPMENT OF PROFESSIONALISM OF THE TEACHING STAFF AT UNIVERSITIES}

Teaching in the field of business education is fundamentally different from the teaching work in higher education. The main characteristic of the teaching work in the sphere of business education is the "combined" nature of work activity - it is determined by the institutional nature of the business education which functions in the space of mutual influence of the two spheres - education and business. Teaching in the field of business education also has a higher dynamic development of competencies in accordance with the constantly changing conditions of the business environment and the functioning of business enterprises. The growth in the level of requirements for educational programs and the quality of teaching by individual consumers and client enterprises requires the management of business schools to develop competitive strategies for the search, selection, evaluation and professional development of the teaching staff of business education institutions on the basis of constantly monitoring the assessments of listeners and ensuring productive interaction between educational institutions and the business community [5].

The main result of the teaching work is the level of development of students' competencies. The results of analyzing teaching work effectiveness and the process of forming the competencies of students at one of Russian universities have shown that it is very important to conduct parallel planning of the process of forming competencies for students and the results of teaching work. This is necessary if we want to improve the results of students' training by means of selecting the teachers. The division of competencies enables to effectively control the process of forming competencies, compile a "roadmap" of competencies, and distribute the teaching resource over semesters of training. Preliminary planning of stages and means of forming competencies helps to optimize the process of distributing the responsibility among teachers for the formation of competencies.

Failures in teaching activities are often connected with teachers' unpreparedness. This happens largely because the majority of faculty members are not aware of the importance of teaching qualifications and competence. Improvement of teachers' professionalism can be considered as one of the most important conditions for good quality education. The high level of teacher training for modern educational activities includes the development of such necessary personal qualities as the ability to grab the audience, high working capacity, the ability to deal with negative actions on the part of students, distractions and strong irritations and to work creatively, having a high emotional status, as well as possessing special qualities of the teacher - excellent knowledge of the subject area and of modern technologies and methods of teaching, the ability to analyze and identify the shortcomings and to further work on these shortcomings. However, often the daily work of a teacher is only of a formal nature [6]. This is due to a number of reasons: 
- Habitual formation of the environment of teaching activity in the traditional mode with a low degree of readiness for changes;

- Lack of motivation;

- Inability to determine the priority direction (the socalled "spraying" in different directions), which leads to getting no tangible result.

A rational choice of pedagogical interaction with students requires not only the assessment of the possible usefulness, but also a thorough analysis of the internal conditions for implementation, as well as a forecast of how the innovation will fit into the pedagogical system of the university. The improvement of pedagogical qualifications causes incomplete understanding, difficulties and, as a result, denial among many teachers. Some of them even need psychological support which can be provided at individual consultations of teachers-practitioners or at special seminars. A lot of teachers are ready to undergo further training in this area.

Such motivations as the desire to avoid negative evaluation during attestation or election to a higher position can have a positive effect, as well as some other motivations of moral and material nature. Without denying the dominant role of internal motives, one should not underestimate the role of motives associated with external factors such as the approval of colleagues, the interest of the heads of the university and its departments [7].

Studying the activity of the teaching staff by representatives of the quality management service of the university can be oriented to two groups of indicators: the qualification characteristics of each teacher and the quality of the training session. In order to obtain the qualification characteristics of the teacher indicators, informative criteria for different categories of teachers are determined and systematized, reflecting the levels of their professionalism. These criteria are used as the basis for calculating the rating assessment, which allows to objectively account for the individual choice of the professional development program. The rating assessment is a generalized conclusion about the results of the teacher's activity on the basis of qualitative and quantitative analysis.

In the system of quality management of education in the university, the specified procedures (rating evaluation and questioning) reveal the correspondence of the operating mode of the university and the development of the processes taking place in it to the accepted management decisions. Performance control gives systematized information, shows the discrepancy between the goal and the result achieved [8]. The system of advanced training for the teaching staff which is aimed at developing the teaching potential of the university should take into account the following aspects:

- The continuity of professional qualities development for the pedagogical staff, implementation of training in various forms (different types of pedagogical workshops, open seminars, individual and group forms of creative dialogue, participation in scientific and practical conferences);

- Organizational and methodological support for pedagogical innovations;

- The use of a decentralized structure of decisionmaking, the transfer of a significant part of the decisions concerning teaching activities to the departments, with due division of rights and responsibilities;

- The development and consistent implementation of adequate forms and methods of stimulating the scientific and pedagogical growth of the teaching staff.

The essential conditions for effective quality management in the university are systematic control and analysis of objective data at all hierarchical levels, since the management process can only be effective if there is a stable feedback that provides reliable information on the state of all subsystems and processes. The functioning of the system of educational processes management at the level of the university will ensure the transition from the analysis of specific problems to a broader view of the quality of education, which enhances the forecasting capabilities and greatly contributes to elaboration of preventive measures. This will make it possible to transfer the management process in education from operational to strategic level.

\section{CONCLUSION}

The systems for assessing the results of teaching work are designed to influence the motivation of teachers to perform activities with varying intensity in accordance with the tasks that the university faces. By introducing effective labor assessment systems and, as a result, an appropriate incentive system, it is possible to form the following types of motivation for teachers to perform their professional activities at a high level:

- Instrumental and financial motivation: the motivation for expecting high wages, readiness for labor intensification as a result of financial encouragement, while the content and quality of work are not the top priority;

- Competitive motivation: the motivation to take a decent place in the university professional rating, as well as in the national or even international ratings of scientists;

- Compensatory and future-oriented professional motivation: the motivation for ensuring the future with a high level of professional achievements to be protected from the possibility of being non-demanded as a specialist.

\section{REFERENCES}

[1] E.Y. Shcherbina, Efficiency of teaching work as a factor of competitiveness of graduates of the university. Journal: scientific 
dialogue. Publisher: Center for Scientific and Educational Projects (Ekaterinburg). Number: 3 (27) Year: 2014. pp: 123-131

[2] N.N. Kochetkova, I.S. Voinov, Management of the efficiency of the teaching staff of the university. Journal: Caspian Journal: Management and High Technologies. Publisher: The Federal State Budget Educational Institution of Higher Professional Education "Astrakhan State University" (Astrakhan). Number: 4 (32) Year: 2015. pp: $34-44$

[3] V.G. Belov, Y.A. Parfenov, E.P. Kosinova and I.M. Gibova, Criteria for assessing the effectiveness of the teaching staff. Fundamental research. 2014, No. 8-4, pp. 981-984.

[4] T.L. Klyachko, E.M. Avramova, D.M. Loginov, Dependence of effective activity on material incentives. Economics of education, 2015, No.2, pp. 63-73.

[5] A.G. Kislov, To assess the effectiveness of the teacher at the university (reading a book of colleagues). Modern Higher School: an Innovative Aspect. 2017, Vol. 9, No. 1 (35), pp. 10-21.

[6] M.V. Gunchenko, Y.V. Skorokhodova, Criterial payment model as a basis for managing the efficiency of the work of teachers in higher education. Crimean economic herald, 2014,.No. 1-1 (08), pp. 146-149.

[7] A.V. Titovsky, G.B. Kondrakov, T.I. Makarenkova, M.V. Alayev, Stimulation of labor activity of the faculty. Bulletin of the Russian Economic University. G.V. Plekhanov, 2016, No. 4 (88), pp. 24-31.

[8] M.A. Masych, M.V. Panichkina, Instruments for increasing the effectiveness of the work of university teachers: the material aspect. State and municipal management. Scientific notes SKAGS, 2016, No. 3, pp. $169-175$. 